\title{
A Review of Multidimensional Scaling in Marketing Research
}

\author{
Lae G. CoOpror
}

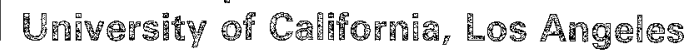

The domain of this review includes the development and application of multidimensional scaling (MDS) in product planning; in decisions concerning pricing and branding; in the study of channels of distribution, personal selling, and the effects of advertising; and in research related to the fact finding and amalysis mission of marketing research. In research on product planning, specific attention is given to market structure analysis, to the development of a master configuration of product perceptions, to the role of individual differences, to representing consumer preferences, to issues in market segmentation, and to the use of asymmetric MDS to study market structure. Regarding fact finding and analysis, this review deals with issues in data collection such as the response rate, time, and accuracy of judgments; the validity, reliability, and stability of judgments; and the robustmess of data collection techniques and MDS algorithms. A separate section on mew-product models deals with the determination of relevant product markets, the identification of determinant attributes, the creation of product perceptual spaces, and the modeling of individual or market-segment decision making. Three trends are discussed briefly; (1) a trend toward finer grained inspection of individual and group perceptions, (2) a trend toward merging consumer level measurement and market level measurements, and (3) a trend toward the study of the creation of new markets, rather than new products in existing markets.

Understanding the choices people make in the marketplace is the main goal of marketing research.

APPLIED PSYCHOLOGICAL MEASUREMENT

Vol. 7, No. 4, Fall 1983, pp. 427-450

(C) Copyright 1983 Applied Psychological Measurement Inc. 0146-6216/83/040427-24\$2.45
How people perceive the altematives from which they choose is a fundamental question for this domain. Multidimensional scaling, cluster analysis, factor analysis, multiple discriminant analysis, and conjoint measurement, as methods for representing perceptions, have all received major attention in the marketing research literature.

The professional marketing research community has not lagged behind the academic community. In a survey of American Marketing Association members who were company marketing researchers or suppliers of marketing research to compamies, Bateson and Greyser (1982) reported extensive relevant applications of 13 techniques. Almost $70 \%$ of the company researchers surveyed had used multidimensional scaling (MDS), with two-thirds of these users finding the techniques relevant to their problems. Almost $80 \%$ had used cluster analysis, $86 \%$ had used factor analysis, and 56\% had used conjoint measurement. More than three-quarters of the users of these techniques found them relevant to the problems the researchers confronted. Research suppliers surveyed had slightly higher usage and satisfaction rates.

Such technological diffusion is more likely to occur when there is a symbiosis between the needs of the marketing manager and the curiosity of the marketing researcher. To understand the symbiosis and to help structure a review of the contributions of MDS to marketing research, it is useful to present a classic conceptualization of the role of the marketing manager. 
In the late 1940s a marketing manager was temed a "mixer of ingredients" by Borden (1964), who designed a list of important elements or ingredients that make up a marketing program and a list of forces that bear on the marketing operation of a firm. The marketing mix includes product planning (e.g., what product lines are to be offered, what markets to enter, and new product policy), pricing policy, branding, channels of distribution (e.g., the paths products take from the manufacturer to the consumer), personal selling, advertising, promotions, packaging, displays, servicing, physical handling, and fact finding and analysis. The market forces that bear on the marketing mix include consumers' buyer behavior (c.g., motivation in purchasing, buying habits, and situational infuences), the trades' behavior (e.g., the structure, practices and atitudes of wholesalers and retailers), competitors' position and behavior (e.g., industry structure and direct competition as well as indirect competition), and govemmental behavior (e.g., the regulatory environment).

On the role of a marketing manager, Borden (1964) stated:

The skillful marketer is one who is a perceptive and practical psychologist and sociologist, who has keen insight into individual and group behavior, who can foresee changes in behavior that develop in a dynamic world, ... His skill in forecasting response to his marketing moves should well be supplemented by a further skill in devising and using tests and measurements to check consumer or trade response to his program or parts thereor, for no marketer has so much prescience that he can proceed without empirical check. (pp. 4-5)

That such a complex and comprehensive mandate for marketing management has fostered the evolution of a specialization in marketing research should come as no surprise. Also contributing to the Zeitgeist were the twin notions that marketing research should not be merely reactive, helping to find a consumer market for the products which spring forth as did Athena, fully grown from the head of Zeus, but rather that marketing research should be proactive in aiding the design of products that better match the needs and desires of consumers.

It was in March of 1964 that Kruskal published his work on nonmetric MDS. By the summer of 1964 data were being collected in six cities to use Kruskal's (1964a, 1964b) algorithm to help design the "perfect cup of coffee" (cf. Brown, Cardozo, Cunningham, Salmon, \& Sultan, 1968). The problem was to array brand-to-brand similarities in a multidimensional space along with the verbal descriptions of product features, then to assess where new products (e.g., new blends of coffee) were judged to fall. When the new coffee blend was found that matched the desired feature descriptions in the judgments of consumers, the share of competitive choices for this new coffee, as well as the source of those choices, could be used to help estimate the market potential of a new brand. The linking of brand perceptions with linguistic descriptions was the key contribution of sociologist and linguist Steffire (cf. Brown, et al., 1968; Silk, 1969; Steffre, 1968). With a linguistic description to help anchor the perceptions of the new product one could go about trying to design packaging and advertising that conveyed the same or similar image as the new product itself. These are important steps in the design of an entire maketing program to convey a desired image.

Stefllre's similarity judgments came from a simplification of the conditional rank order task. In the conditional rank order task each stimulus serves in turn as the key, and the other stimuli are ranked from the most similar to the key to the least similar to the key. In Steffre's simplified version each brand served in turn as the key, and the respondents merely checked the other brands in the list that they considered "most similar to" the key. Aggregated over individuals, these data correlated rather well with expensive brand-switching data from consumer purchase panels. Linguistic descriptions (e.g., "a very dark rich coffee") were imbedded into the space in a seemingly ad hoc manner, individual differences were aggregated away, no account was taken of the substantive asymmetries of the switching data, and preferences were not formally conmected to the sparial representation, but the ideas fit together in a compelling fashion. The work dealt 
simultaneously with product planning, advertising, and packaging; and with the market forces of the consumer's buyer behavior and the competitors' position and behavior.

The early reviews and overviews (Frank \& Green, 1968; Green, 1970; Green \& Carmone, 1969; Green, Camone, \& Robinson, 1968; Neidell, 1969) made marketing researchers aware of the broad spectrum of problems to which MDS could be applied. The early books and chapters (Green \& Carmone, 1970, 1972, 1973; Green \& Greenberg, 1974; Green \& Rao, 1972b; Green \& Wind, 1973; Greenberg \& Green, 1974; Steffre, 1972) filled in the technical picture, and along with Green (1975a), delineated lingering issues such as interpretation of MDS configurations, stability and reliability, the relation of perceptual analyses to choices, and issues of individual differences.

This review will deal with the problems and proposed solutions as they developed principally in the joumal literature. The marketing mix elements will serve as an organizing theme.

\section{Proulde PPlanining}

Product planning involves many different stages and problems. In this section the studies have been organized into interrelated subtopics concerning (1) market structure, (2) the evolution of a master configuration for perceptions, (3) individual differences, (4) preferences, (5) market segmentation, and (6) market structure models using asymmetric data. Models for new product plaming, and strategic models linking product planning to other elements of the marketing mix, will be reviewed after research on other elements is reported.

\section{Market Structure Amalysis}

Market structure analysis deals with issues in product planning as well as issues in the understanding of the forces of competition. Two points are illustrated by Klahr's (1970) study of major brands in the cigarette market. Klahr showed that when the dominant distinguishing feature of brands is a binary characteristic (e.g., filter tipped versus nonfilter), nonmetric MDS algorithms can produce degenerate results, progressively reducing the withincategory distance and increasing the between-category distance until two points in space represent the two categories of brands.

The first point is that marketing researchers received very early waming of this kind of degeneracy. This degeneracy made individual level analysis tenuous, but 5 of the 10 judges in Klahr's study had significant correlations between their preference scales and the distance of each brand from their most preferred brand in the individual spaces. The most preferred brand was used as a surrogate for an ideal brand.

The second point is that it is practically impossible to discuss the structure underlying similarity judgments without dealing with the relations of perceptions to preferences. Klahr's (1969) study of how college admission officers judged applicants served to underscore that not just brands, but the perceived interrelations among many sets of choice altematives, could be represented with nonmetric MDS. Nonmetric MDS was thus useful in understanding how people make choices.

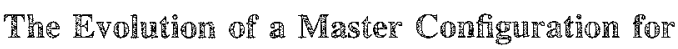 Perceptions}

In this subsection are reported a series of studies by Green and his colleagues which have provided leadership in this field and have brought richer meaning to market structure analysis. The Green and Carmone (1968) study of the structure of the computer market over time introduced product life cycle analysis using nonmetric MDS. They compared obverse factor analysis (i.e., factor analysis that explores the structure underlying brands rather than the structure underlying descriptive variables) with TORSCA (Young \& Torgerson, 1967) and parametric mapping, i.e., a nonmetric MDS routine that emphasizes maintaining local monotonicity but relaxes monotonicity for very dissimilar objects (Shepard \& Carroll, 1966; cf. Coxon, 1982, p. $159 \mathrm{ff}$.). Rather than just looking at the trends in aggregate sales over time to reflect where a product was in the cycle of introduction, growth, maturity, and decline, comparisons based on product characteristics in an innovative market, such as 
computers, could reveal this cyclical structure. Profile distances from 75 nomalized characteristics were calculated over the 12 computers, and the 12 $\times 12$ distance matrix was analyzed by all three methods. Obverse factor analysis and TORSCA found clusters of three generations of computers. Parametric mapping did not. Emphasis was placed on multimethod comparisons when little was known about the match of the functional relations underlying objects to the assumptions implicit in an analysis.

Green and Maheshwari (1969) investigated the perceptions of common stocks as investment vehicles. They used multiple regression to imbed property vectors into the two-dimensional space. The ratings of each object on each property were the dependent measures, and scale values of the objects on each dimension were the independent variables. The multiple regression weights were used as the coordinates of the property vectors. As was also found by Krampi and Williams (1974), the oblique vectors of perceived growth and perceived risk correlated highly with the two dimensions of the configuration. For each of the two groups in this study, preferences were imbedded into the space using Carroll and Chang's (1967) external analysis of preferences. For one group, a vector model indicating the direction of preference gave an adequate representation. For the other group, ideal coordinates were appropriate. On one dimension the closer stocks were to an ideal location, the more preferred they were; whereas on the other dimension the closer stocks were to an anti-ideal location, the less preferred they were.

Green, Maheshwari, and Rao (1969b) used nonmetric MDS to investigate the notion that consumers purchase products that have images similar to their own self-image. By scaling average similarities, imbedding property vectors for interpretation and using self-image ratings as a surrogate for preference, they found that some consumers do and some do not desire automobiles with images similar to self-images. This equivocal conclusion helped foster an understanding of the need to represent the systematic nature of individual differences in perception and preference.
Again working with automobiles, Green, Maheshwari, and Rao (1969a) collected similarities, preferences, and semantic differential ratings from two groups of respondents. Each group rated 11 cars from a 17 -car list, with 5 cars in common across groups. They demonstrated stability for the product spaces derived from the similarity measures compared to the spaces derived from profile distances over 20 semantic scales. The set of 5 cars remained stable over changes in surrounding stimuli. Comparison of TORSCA versus parametric mapping showed at least one stable dimension across the two methods.

Green and Carmone (1971) used a three-way INDSCAL analysis to demonstrate that task-specific ratings tap only a subset of the dimensions in the conceptual space of the individuals. Hustad, Meyer, and Whipple (1975) integrated eight usage occasions and context-specific ideal points into an analysis of market structure. Mauser (1980) scaled political candidates along with campaign themes to discover themes that were highly popular and that appealed to a candidate's current supporters.

Green, Wind, and Jain (1972) demonstrated that heterogeneous collections of stimuli can be meaningfully scaled in a common space. Respondents judged the relevance of common personality traits to "other persons" " choices of automobile brands, occupations, and magazines. For each of five cars a respondent was shown a list of 14 personality traits and asked to rank the traits according to the likelihood that a person who owned that car would possess that trait. This was repeated for five occupations and then for five magazines. Then each respondent was shown, sequentially, two sets of 25 cards each: all combinations of five magazines and five cars formed the first set and five occupations together with five cars formed the second set. These were sorted into four ordered categories to reflect the probability that a person with a particular occupation would own a particular car or that a person who read a particular magazine would own a particular car.

Even though the data were ranked and ordered categories, all variables were converted to standard scores and the Howard-Harris (1966) clustering 
routine was used to find four homogeneous groups of individuals. Within each group the original 14 trait rankings were averaged over individuals for the 15 cars, occupations, and magazines. Profile Euclidean distances were computed on these average ranks. Acceptable three-dimensional stresses for the TORSCA-8 solutions were found for each group. The occupation-car and magazine-car ordered category scales were averaged within groups. The complex matrix of associations would have nine sections for the Cartesian product of the set of occupations with the set of magazines and the set of cars. With only the occupation-car and magazine-car sections being of interest, the sublist splitting feature of M-D-SCAL V (Kruskal, 1968) was used so that the nonmetric constraints were maintained only over the two sections. Good fits were again obtained in three dimensions for each group.

The two configurations for each of four homogeneous groups of individuals were used as eight psuedo-subjects of an INDSCAL (Carroll \& Chang, 1970) analysis by computing interobject distances in each configuration. The three-dimensional INDSCAL solution was comparatively easy to interpret in terms of (1) a prestige dimension, (2) a sportiness-versus-conservatism dimension, and (3) something akin to a masculinity-femininity dimension. The respondents' perceptions of object congruences (occupation-car pairs and magazine-car pairs) "were highly associated with the relative nearness of these objects in an independently obtained (reduced) trait space" (p. 208).

If the Perreault and Young (1980) illustration of ALSOS had been available earlier, the rank-order data would not have forced the methodological choices made here. Averaging rank-order data is not a very desirable methodological alternative. Further, profile distances can produce comparatively low stress solutions while doing a relatively poor job of recovering structure (Drasgow \& Jones, 1979). Despite the information loss inherent in the procedures, it does appear that quite heterogeneous item collections can be meaningfully displayed in a common space.

Green and Rao (1972a) used a similar series of methods to develop a master configuration for 15 bakery items that might be eaten at breakfast. Directly judged similarities for men and women in the respondent pool were averaged separately and scaled in three dimensions using TORSCA. Rating of the bakery items on 7-point bipolar scales were averaged for men and women; Mahalanobis distances were computed over 10 scales and the results also scaled in three dimensions by TORSCA. Finally, preference rankings of the items on each of six different usage occasions were averaged for men and women and parametrically mapped onto a stimulus configuration in three dimensions.

The Euclidean interobject distances from these 16 scaling solutions became the input to an INDSCAL analysis. The resulting dimensions (1) separated the meal type items from the snacks, (2) separated the sweet from the nonsweet items, and (3) separated the cake-like items from the breadlike items. The dimensions were correlated. The pseudo-subject dimensional saliences were easily interpretable and gave a clear representation of how different usage occasions corresponded to different dimensional saliences. It is difficult to assess what impact the averaging of ordinal ranks had on these results. Arabie, Carroll, DeSarbo, and Wind (1981) reanalyzed these data and found five overlapping clusters of pastries, food spread with butter, toasted foods, sweet foods, and relatively simple bread foods.

The last two studies involve the imbedding of features into a product space. Green (1974) collected subjective ratings from respondents regarding (1) the degree of belief that if a particular feam ture $i$ is present, then feature $j$ would also be present in a typical brand, (2) the degree of belief that a particular brand possesses a particular fearure, and (3) the desirability of a particular feature in each of a series of usage occasions. For $m$ features, $n$ brands, and $p$ usage occasions this results in an $(m+n+p) \times m$ data matrix for each respondent. Green based his analysis on the average of the subjects' matrices. The two-dimensional configuration from M-D-SCAL $V$ was interpreted as an approximate radex. The circumplex notion did seem to fit to a certain extent. Associated items 
frequently showed up as neighbors in an MDS configuration. Neighbors connect to other neighbors, forming something like a circumplex regardless of whether or not a simple interpretation exists for the dimensions. In any case, Green's method of imbedding features into a product space is much less ad hoc than Stefflre's method (cf. Brown et al., 1968, p. 464).

Finally, Green, Wind, and Claycamp (1975) developed a master configuration from the same basic data as described above, but with different analyses. Ross and Cliff's (1964) generalization of the interpoint distance model was used to develop three feature configurations, one from each section of the $(m+n+p)$ data matrix for the average individual. Interfeature distances in these three configurations became psuedo-individuals in an INDSCAL analysis. A five-dimensional solution resulted, with two common dimensions (i.e., naturalartificial and rich-light), and three solution-specific dimensions. The two common dimensions became the target for fitting brands into the space with PREFMAP (vector model) and then for fitting desirability ratings for features of the favorite brand into the space using the ideal point version of PREFMAP. From this master configuration can be judged the aggregated association of features with brands as well as the features desired in a particular favorite brand. Arabie et al. (1981) suggested that overlapping clustering in this master configuration wolld be particularly interesting.

Probably the least desired result of an MDS study is a product or brand map that seems uninterpretable. The series of studies just described in this subsection offer ways of enriching the interpretability of a perceptual space by positioning features of products, associated life style items, and preferences into the map alongside the brands.

\section{Individual Diprerences}

Although studies of the systematic differences among individuals appear throughout this review, three studies are reported here to introduce the topic. In the first, Kinnear and Taylor (1973) used a response measure, an ecological concern scale, to segment the sample. In the second, Rao (1972), induced individual differences by an experimental design involving the information each respondent received. In the third study Ritchie (1974) formed groups of individuals by clustering their dimensional weights from an INDSCAL analysis.

Kinnear and Taylor (1973) studied the effects of ecological concerns on the perceptions of consumers of laundry detergents. At the height of concern about water pollution from phosphates and enzymes in detergent, they sampled 500 members of a consumer panel. A behavioral and autitudinal scale of ecological concern was used to segment the sample into five subgroups expressing increasing ecological concem. Similarities judgments for five phosphate detergents, two nonphosphate products and an explicit rating of an ideal detergent were collected before the autitudinal measures were taken. The three-dimensional INDSCAL solution fit quite well and seemed interpretable in terms of a phosphate dimension and two cleaning power dimensions. The analysis of dimensional weights for the five groups demonstrated that the higher a buyer's ecological concern, the more salient is the ecological dimension in perception and the greater is the perceived similarity of brands that are ecologically nondestructive.

Rao (1972) induced individual differences through experimental manipulation of the amount and kind of explicit information provided as a basis for similarity ranking of 12 cars. The $2 \times 2 \times 2$ design (with two empty cells) varied: brands identified or not, semantic descriptions provided or not, and profile descriptions provided or not. The cell with no brands identified, no semantic description, and no profile description was deleted from the design for obvious reasons; and the condition containing both semantic descriptions and profile descriptions was deleted to avoid information overload. The three-dimensional INDSCAL solution was interpreted as (1) luxuriousness, (2) domestic versus foreign manufacture, and (3) size. The absence of brand name de-emphasized salience of the origin of manufacture; whereas without semantic descriptions the luxuriousness was de-emphasized; and without the profile information size was deemphasized. The nature of the information in each category made these findings quite reasonable. The 
salience differences were still significant after 10 covariates were introduced to account for (nonexperimental) individual differences among subjects.

Ritchie (1974) studied the nature of individual differences in perception of 12 leisure-time activities. Over three trials he found that there was sigmificantly less variation within individuals in INDSCAL saliences than between individuals. However, when he formed five perceptual groups using Johnson's (1967) hicrarchical clustering on dimensional weights, he found that the five groups did not differ between groups in interest or participation in the activities and for the most part did not differ in the 18 Rokeach measures of personal values. The problem here may stem from Ritchie's use of hierarchical clustering on differences in dimensional weights. Two individuals on a vector, just differing in length from the origin, will have the same perceptual configuration. They will differ only in the extent to which the scaling model fits the approximate individual scalar products matrix. So differences in perception are better measured by the angle in radians between the vectors for two individuals.

\section{Prererences}

Preference is a key concept for understanding the linkage of perceptions to choices. Four approaches to preference research are considered in this section:

1. The huge marketing literature on conjoint analysis merits its own review and is just briefly mentioned here.

2. The analysis of micropreference structures investigates how individual level utility scales can be developed from preference judgments.

3. Internal analysis of preferences attempts to use the preference judgments alone to develop configurations of brands. Some intemal analysis techniques attempt to array directions of increasing preference into the brand maps (i.e., vector preference model); whereas other intemal analyses of preference attempt to represent the brand perceptions, along with ideal points for individuals or groups, in a joint space.
4. External analysis of preferences attempts to map preference vectors or ideal points onto predetermined perceptual maps to create joint space representations.

Although the first two approaches are treated in subsections of their own, the last two approaches are considered in three subsections on joint space analysis.

Conjoint analysis. Green and Rao (1971b) introduced the marketing research community to conjoint measurement. They tied the general conjoint analysis model to the specific nonmetric MDS model by multidimensionally scaling law enforcement of ficers' judgments of the severity of different forms of drug abuse. Green, Wind, and Jain (1972) used MDPRER, Chang and Carroll's (1968) intemal analysis of preferences, to represent preference heterogeneity in what was basically a conjoint analysis study of dessert preferences; and Green and Devita (1975) used MDPREF on an interaction preference table to provide a graphical aid for interpreting interaction effects in an extended conjoint analysis model.

Micropreference structures. Bechtel and O'Connor (1979) developed analysis of variance (ANOVA) tests for micropreference structures (cf. Bechtel, 1976). The first test on the graded paired comparison preference ratings (i.e., ratings of the strength and direction of preferences) attempts to determine individual level utility scale values for the objects. In an application to soft drink preferences from Cooper (1973), 51 of the 52 respondents had statistically significant utility scales. They were then retained for further tests, which attempted to determine if individual utility scales were mediated by a vector model using perceptual attributes. In this case the perceptual attributes were the first dimension scale values (a cola versus noncola dimension) for the soft drinks from a metric scaling of similarities (cf. Cooper, 1972) and the mean familiarity ratings of the soft drinks. Under the hypothesis of a common perceptual configuration using these two atributes, the $A N O V A$ model rejected the fit of the vector model at the individual level in this example. The preferences seemed too idiosyncratic to be predicted from a common perceptual configuration. 
Bechtel and O'Connor (1979) also provided a segment-based analysis of Dutch schoolchildren's national preferences. The preference measures came from the logit of the proportion of children in segment $i$ preferring nation $j$ to nation $k$. The overall utility scale was statistically significant, as were the segment utility scales for Grades 2 through 6. "Urility scales broaden strikingly with increasing age, indicating better preferential discrimination among older children" (p. 255). There was also a small, but statistically significant, amount of systematic unscalability. (Systematic unscallability was also significant in the aggregate of soft drink pref. erences.)

Bechtel's (1976) tests allow for very fine grained assessment of the fit of particular multiattribute structures to individual or segment preferences. Bechtel (1981) further developed this logit preference model.

Joint space analyses. The typical integration of similarities and preferences is illustrated by Green, Carmone, and Fox (1969), who used TORSCA on similarity judgments among 38 television programs and followed with Carroll and Chang's (1967; Carroll, 1972) external analysis of preferences (PREFMAP). The Doyle and McGee (1973) study of the market structure of convenience foods and Percy's (1975) study of potato side dishes are similar examples.

Best (1976) took a much closer look at joint space modeling as a porential theory of individual choice. Although price considerations did not enter his study, Best did track choices among eight soft drinks over a 12-week period (i.e., 2 weeks to adjust to the apparatus and two 5-week consumption periods). At the midpoint of each consumption period, conditional rank order similarity judgments and rank order brand preference were collected. From the first consumption period a readily interpretable three-dimensional INDSCAL solution was selected. PREFMAP was used to imbed ideal points for all 77 individuals.

Inspection of the relation of ideal distances and choice proportions from the first period led to the specification of five different mathematical functions relating distance from the ideal point to product choice. Ten people were represented with a disjunctive model (i.e., the brand closest to the ideal point dominated the choices). Forty-five people were represented by a hyperbolic model (i.e., choice probability tapered off dramatically with increasing distance from the ideal point). Four people were represented by a conjunctive, relevant set model (i.e., all brands within a certain distance from the ideal point had an equal probability of being chosen). Four people were represented by a linear model. A polynomial model was needed to represent 10 people; these people were dieters who had nondiet ideal points for preferences. Brands very near their ideal points had a low probability of being chosen, as did brands that were very far away. The diet brands nearest the nondiet ideals had the greatest probability of being chosen. Finally, four people were represented by a random model.

Thus, 73 of 77 models provided sensible calibration results. Although brand preferences were stable over consumption periods, brand choices were not. Fifty-seven of the 73 provided significant prediction of future brand choices. The drop-off was partly attributable to six individuals who went of their diets in the second consumption period.

Huber (1975) compared five models for predicting preferences for different levels of tea and sugar in iced tea. All models were developed on 16 experimental compounds in a lattice design (based on the logs of the sugar concentration and tea concentration) and were used to forecast preferences for seven validation examples within the lattice. The three best models were an ideal point model mapped onto the physical space, a maive model that simply averaged preferences for the four nearest neighbors, and an additive part-worth model. Not too far behind in forecasting ability were an ideal point model in a psychological space and an additive model weighted by perceptual scale values. For all but the naive model it was possible to compare metric versions for the forecasts of each model with corresponding nonmetric versions. Although there was considerable congruence between the results within models, the metric version produced consistently superior results.

Marketing researchers developed alternatives to the multiple regression approach of PREFMAP. 
Srinivasan and Shocker (1973) developed a linear programming technique for the external analysis of ordinal preference judgments, which they termed LINMAP (see Hopkins, Larreche, \& Massy, 1977 , for a typical application). Pekelman and Sen (1974) developed a mathematical programming model that was very similar to LINMAP.

Explicit versus implicit ideal points in joint space representations. Another approach to joint space analysis requests that the respondent explicitly rare an "ideal" product along with the other objects being compared, as was done by $\mathbb{K}$ innear and Taylor (1973). The ideal point for the respondents is the position of the "ideal" product in the perceptual space. Day (1972) compared cognitive consistency theories of attitude structure and multidimensional scaling using this approach. Specifically, he was interested in comparing the representation of preferences obtained from Lehmann's (1971a) ideal distance model (based on specific attribute measurements) with two nonmetric joint space representations: one with an explicit "ideal" product rated along with the other objects and the other representation obtained through extemal analysis of preferences.

The heuristic comparison between Lehmann's model and the nonmetric MDS approaches favored MDS "because they [MDS approaches] demand less complex and fragmented data from respondents" (p. 284). The explicit versus implicit ideal point comparison revealed a modest displacement between the average explicit and average implicit ideal points. However, the rank orders of the preferences from the two points were almost perfectly correlated. Further, Lehmann obtained considerable variation in preferences depending on the specific usage context, i.e., preference judgments were not context-free.

Holbrook and Williams (1978) compared the INDSCAL representation of 12 female singers collected with and without explicit ideal points. Their concern was with the affective halo that sornetimes surrounds multiattribute judgments of brands (Fry \& Claxton, 1971, went so far as to average scores for only those respondents who did not prefer a brand in order to avoid halo effects in the attribute space they compared to their MDS representation).
Holbrook and Williams found that the inclusion of an explicit ideal point did not distort the configuration of the other 12 singers. A clear two-dimensional interpretation (i.e., ethnic membership and contemporaniety of style) appeared in both configurations. The 66 intersinger distances correlared around .95.

The explicit ideal point approach is quite interesting but does create some problems. It is inappropriate to consider one person's judgments involving explicit ideal points to be comparable to other respondents. Averaging across respondents can distort the position of the explicit ideal point even if the positions of the other products are undisturbed.

Recent developments in joint space analy. sis. Some of the more recent applications of joint space analyses have come from Moore, Holbrook, and their colleagnes. Moore, Pessemier, and Little (1979) applied Schönemann and Wang's (1972) unfolding model in three product classes: cake mixes, household cleaners, and toothpastes. They used Pessemier's dollar metric for graded paired comparison preferences in which respondents estimate a monetary value for the difference in their preference (cf. Pessemier, Burger, Teach, \& Tigert, 1971). After development of the configurations, interpoint distances in the joint space were used to estimate purchase probabilities. They noted the tendency of the dollar metric to underpredict preferences for more preferred brands and to overpredict those for less preferred brands. Using a power transformation of the scale values to predict purchase probabilities corrected substantially for the bias. The corresponding predictions were made from the nonmetric unfolding option of KYST. For toothpastes and cake mixes the Schönemann and Wang (1972) model produced statistically superior predictions. For household cleaners KYST was slightly, but not significantly, better.

Holbrook, Moore, and Winer (1982) applied Levine's (1979) procedure for developing joini space solutions from "pick any" data. In marketing research this is like a "relevant" set model in which a consumer picks from a large list or simply recalls all the brands he or she would consider purchasing. In Levine's model a person's ideal point is located 
at the centroid of all the brands he or she picks, and a brand is located at the centroid of all the people who pick it. Holbrook, Moore, and Winer (1982) applied the model to the representation of radio listenership data, a large stimulus set, which no one person could judge individually. They scaled 1,380 respondents based on 25 radio stations, demonstrating the utility of the method when most other methods are inappropriate or impractical. They also applied the analysis to soft drinks and compared the representation to that obtained using KYST. The results were quite similar when both techniques could be applied. The problems that can be encountered with Levine's (1979) technique stems from (1) individuals who only rate one brand; (2) instability of the much less popular brands (since their positions may be underdetermined); and (3) the pulling of the most popular brand to the center of the configuration (e.g., Crest was in almost everyone's relevant set and thus positioned at the centroid of the respondents).

Moore (1982) and Moore and Holbrook (1982) studied the predictive power of joint space models using "hold out" brands and hold out concepts. This approach, which was also used in the validation of the Pekelman and Sen (1974) mathematical programming model for attribute weights, tries to validate the predictive ability of a joint space representation by assessing how well preferences or choices for different brands can be forecast once they are placed into existing joint space configurations. Moore and Holbrook found a marked deterioration in predictive power when joint spaces were derived on real objects and used to predict new concepts. They have suggested conjoint analysis as a more sound approach.

Moore (1982) found that perceptual spaces built from discriminant analysis used with external vector models performed better across frequently purchased goods, compact cars, and services. Whereas the conjoint model or multiple discriminant analysis may be superior in these applications, the use of holdout brands is questionable. Without a model for how preferences change over the sets of brands or concepts that form the judgment contexts, one should be wary of holdout brands. Their use basically assumes what is rarely true, i.e., that pref- erences and choices are context free (cf. Cooper \& Nakanishi, 1983). New-product models, discussed at the end of this review, need to deal specifically with this issue. Even in a new-product context, however, it is most often only one additional choice alternative that the context must absorb, not six breeds of dogs, as in Moore and Holbrook (1982), or an unspecified number of frequently purchased goods, compact cars, and unnamed services, as in Moore (1982).

\section{Market Segmentation}

Johnson (1971) said, "market segmentation analysis refers to examination of the structure of a market as perceived by consumers, preferably using a geometric spatial model, and to forecasting the intensity of demand for a potential product positioned anywhere in the space" (p. 13). Accordingly, Johnson discussed the uses of MDS and other mapping techniques in a manner very similar to market structure analysis, product positioning analysis, and any of the joint space methods previously discussed.

A more traditional approach to market segmentation has been presented by Wind (1978). He indicated that the classic price discrimination model provides a major theoretical rationale for the segmentation concept. Most simply, the price discrimination model rests on downward sloping demand curves in a plot of price $(y)$ versus quantity $(x)$. Even at a high price, some individuals would demand a product. As price drops, the quantity demanded would increase. With a single fixed price for a product, there is no ability to retrieve the "consumer surplus" (i.e., the area in the plot above the price line but below the demand curve). From this point of view, market segmentation becomes a strategy for differentiating consumers so as to retrieve as much as possible of the consumer surplus. Thus, Wind's discussion of the uses of MDS focused more on the grouping of consumers than the positioning of products. The same physical bundle of benefits may need different packaging, promotion, advertising, pricing, and distribution through different retail outlets to attract different consumer segments. He foresaw great potential for 
the use of overlapping clustering in this domain.

Young, Ott, and Feigin (1978) differentiated segmentation on generic benefits from productusage-purpose segmentation and from styling segmentation. The latter case is for products in which "the style, looks, appearance, or image is the overriding criterion of marketing success" (p. 410). 斯 is in this type of segmentation that they deemed multidimensional scaling more appropriate.

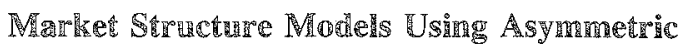 Data:}

Lehmann's (1972) study of market structure using brand switching data demonstrated the different emphasis transition data gave to a nonmetric MDS solution. The emphasis on interbrand substitutability gives results more akin to preference mappings than to similarity scalings (cf. Cooper, 1973). Lehmann's (1972) analysis, however, actually eliminated the asymmetries by forming a weighted average. MDS analyses that maintained the basic asymmetries of brand-switching data are a very recent development. Harshman, Green, Wind, and Lundy (1982) recently introduced the DEcomposition into DIrectional COMponents (DEDICOM) model to the marketing literature. They reported a reanalysis of part of the free-association data from Green, Wind, and Jain (1973) and an analysis of car trade-in data from the 1979 model year. Brandswitching data are very important in marketing research, and the DEDICOM model should enjoy wide use. It is, however, quite different from the sparial MDS model that marketing researchers have come to understand in that it requires ratio scale data. Although some discussion of its applicability to interval scale data is presented, marketing researchers would be well advised to apply DEDICOM to the obvious and available frequency-ofpurchase data or transition probability data. As a hybrid between MDS and factor analysis, the use of interval scale data calls for "factoring" the double-centered score matrix. The model for the factoring of double-centered score matrices is very complex (Tucker, 1956, 1968). There should be many applications of DEDICOM in marketing using the data for which it is primarily intended. The analysis of trade-in data for cars is an excellent example of the kind of thinking required to understand asymmetric flows.

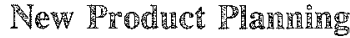

Although the comprehensive new-product models are discussed at the end of this review, there is other research worth noting here. Morgan and Purnell (1969) are often cited for their research on isolating openings for new products in multidimensional space. They actually used factor analysis and cluster analysis to get their product spaces. Lehmann (1974) investigated the usage of TORSCA on linear and polynomial intercorrelations as an altemative to factor analysis in a new product setting. Albers and Brockhoff (1977) structured the new product positioning issue as a mixed integer programming problem (cf. Pekelman \& Sen, 1974). Roberts and Taylor (1975) used multivariate analysis of variance (MANOVA) to show that design effects of new products can be traced by MDS and are open to statistical confirmation. Silk and Urban (1978) just mentioned the role of MDS in new product development; their illustration of the ASSESSOR model used constant sum scaling of preferences, rather than MDS.

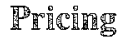

The two pricing studies reported here rely on the Lancaster model (1966a, 1966b, 1971), Ryans's (1974) description of Lancaster's approach was simply:

In contrast to the traditional economic theory of consumer demand, which treats the products themselves as the basic unit of analysis, Lancaster's theory is based on viewing products as bundles of product characteristics. Lancaster assumes that these characteristics are objective, measurable attributes of the product. (p. 435)

Ryans proceeded by invoking the limited information-processing capacity of consumers. Durable goods have many objective, measurable characteristics, and the consumer will probably rely on only a few "perceived" characteristics. These per- 
ceived characteristics were represented with nonmetric MDS in Ryans's study.

Lancaster further assumed that "individuals do not differ in their assessment of the amount of characteristics possessed by a given product" (Ryans, 1974, p. 435). Ryans dealt with this behaviorally unrealistic assumption by forming clusters that were perceptually homogeneous and by analyzing each cluster separately. Ryans's model assumed that a consumer buying a durable good purchased a brand and the other goods and services that together maximized his/her total satisfaction while meeting his/her budget constraint. Thus, any money conserved is used for utility generating purposes. The analysis group rated 12 electric blenders. The three validation groups rated 13 blenders, with the last blender presented with three different prices but with the other product characteristics the same. The similarity ratings on which the product space was developed were collected before the price information was introduced. After the introduction of price, rating scale judgments were collected, followed by preference rankings.

The data collection procedure allowed the testing of two assumptions. The first assumption is that the introduction of a dynamically continuous innovation (i.e., a new product with a combination of features that are also present in possibly different amounts in other products in the market) will not affect consumers " perceptions of the characteristics of other products. A good congruence between the 12-product MDS solution and the 13-product solution supported this assumption. The second assumption was that price would not act as a surrogate for quality and thereby affect the perceived amounits of the other characteristics possessed by the new product. That is, the different price tags would not result in different atribute ratings for the same product. Only the attribute scale dealing with high price versus low price varied significantly over validation groups. Ryans (1974) estimated a quadratic utility function (PREFMAP-Model I; Canoll, 1972) on the positions of the brands in a three-dimensional space from M-D-SCAL-5M. The utility function and price were used to predict the rankorder preferences for the new product among the 12 other products. The STRESSes of the solutions for the various clusters seemed somewhat high, and the overall predictions of rankings from the quadratic utility formulation seemed modest. The best prediction, however, occurred in the proportions of first, second, and third rankings, which is the arena of greatest interest.

Hauser and Simmie (1981) postulated a simplified lens model of consumer decision making. Physical features and psychosocial cues lead to perceptions, which in turn lead to preferences. Constraints such as budget join preferences in leading to choice, and choice feeds back to perceptions. Expressing the belief that good models exist for the other linkages, Hauser and Simmie concentrated on the mapping of physical features onto perceptions. To generalize the notion of an efficient frontier in perceptual space for the "rational consumer" requires the heroic assumption that an absolute origin can be found for the spatial representation. Thus, in the case of analgesics, gentleness and effcacy dimensions could be transformed into gendleness per dollar and efficacy per dollar. The "per dollar" notion is needed in their analysis to make possible the definition of an efficient fromtier for the decisions of a "rational consumer." Since the origin of MDS configurations is arbitrary, MDS does not seem to be a candidate for constructing the perceptual spaces on which the Hauser and Simmie arguments are based. Neither, then, are the spaces derived from factor analysis or multiple discriminant analyses. These are not techniques that yield ratio scaled dimensions.

Although the issue of locating the origin to the perceptual space makes it difficult to understand the applications of rational consumer theory, one of Hauser and Simmie's (1981) theorems deals with consumers, rather than with the convenient fiction of "rational consumers." Their third theorem states:

If the consumer evaluates products in perceptual space, then any consumer analysis that does not consider the perceptual mapping, $\mathbb{F}$ (from physical characteristics to perceptual positions), could identify "consumer optimal" combinations of product which are not efficient....(p.41)

This theorem, which they prove by counterexample, has very important implications. Alhough, 
for the "rational consumer" optimality in the perceptual space implies optimality in the space of physical characteristics, for the real consumer the perceptual analysis holds primacy. Whenever perceptions mediate preferences, the perceptual space is the place in which optimality analysis should occur.

Understanding the impact of pricing on brand perception is problematic within the traditional MDS framework. Price as an attribute of a brand seems much easier to study experimentally by using conjoint measurement designs or by using multiattribute choice models (cf. Cooper \& Nakanishi, 1983). One area seemingly ripe for investigation is how price sensitivity might vary with perceptual position (e.g., proximity to an ideal point). Such a study would parallel Clarke's (1978) analysis of advertising effectiveness by perceptual position, discussed below in the section on advertising.

\section{Bromding}

Although selection of a brand name for a new product is one of the tasks Stefflre (1968) and others have undertaken within a MDS framework, no studies have been published, to the author's knowledge, which deal solely with other aspects of the problems of branding.

The selection of trademarks is an area in which the relation of visual images and the semantic image they connote could be important. The Young, Ott, and Feigin (1978) study indicating the utility of MDS in segmentation based on style or image seems to highlight some potential uses of MDS in evaluating trademarks. The Green and $\mathrm{Mc}$ Mennamin (1973) approach to advertising problems, discussed below in the section on advertising, could also be used for many problems in branding.

The Rao (1972) study, which included a manipulation of whether or not brand information was provided along with semantic descriptions or profile description, indicated some potential uses of MDS in determining the benefits of various branding policies.

\section{Chananels of Distribution}

Products flow from the manufacturer to the consumer through the channels of distribution. The studies that deal with this topic focus mainly on the relations among different retail outlets. Though market segmentation by types of retail outlets is very clearly within the "price discrimination" approach to segmentation (cf. Wind, 1978), no MDS research was found on this topic.

MacKay and Olshavsky (1975) studied the differences between cognitive maps of retail locations based on MDS of proximity judgments and those based on hand drawings. They found that although hand-drawn maps were more like physical maps than are MDS maps, the MDS maps related more closely to preferences and actual shopping behavior. Olshavsky, MacKay, and Sentell (1975) found that distances from MDS maps correlated better (more negatively) with shopping behavior that did distance from actual maps.

The classic example of a necktie that sells at one price in a department store and at a much higher price in a men's speciality store, indicates some interesting possibilities for MDS research involving channels of distribution. Part of a product or brand image might interact with the images of different retail venues. Research that required judgments on the compatibility of brands with different retail outlets could lead to joint space representations or master configurations that would be useful for marketing decision making.

\section{Personal Selling}

Only two MDS studies related specifically to personal selling. Turner (1971) used nonmetric MDS to infer the number and kinds of criteria that individual salesmen used in evaluating their customers. Such an analysis becomes very similar to Klahr's (1969) study of the evaluation criteria of college admissions officers. Green and McMennamin (1973) took a different approach in one of their examples of market position analysis. A large computer firm hosted a study that first mapped the physical characteristics of the computer and its competition into what they called a "performance 
space." The similarity judgments on the computer models were collected from salesmen, customers, and noncustomers:

The sales personnel's perceptions agreed most closely with the objective (performance) positioning of the computer models. However, the firm's customers' perceptions disagreed in significant ways with the sales personnel's perceptions, suggesting that the sales people were not emphasizing certain performance characteristics of the company's line that would enhance customer satisfaction. (p. 502)

Interpretation of the separate analyses suggested specific differences in orientation of customers and noncustomers.

\section{Advertioning}

There are three areas in which MDS has been used as part of advertising research. The first involves how MDS can be used to track the effectiveness of advertisements in repositioning or changing a brand image. The second area deals with the compatibility of atributes or slogans with the perceptual image of a brand and the competitive brands. The third area deals with how advertising effectiveness varies with perceptual position.

In the first area there are two studies: Smith and Lusch (1976) and Perry, Izraeli, and Perry (1976). Smith and Lusch (1976) tried to use nonmetric MDS to assess how advertising can position a brand. Ligget \& Myer wanted L\&M cigarettes to be considered a "full flavored" cigarette. They changed the tobacca blend, filter, and package design, and launched a "massive advertising campaign" (p. 39). The promotion occurred in selected West Coast cities, which enabled Smith and Lusch to study perceptual positions before and after with a control group. Smallest Space Analysis (SSA; Gutman, 1968) on the similarity ratings before the campaign confirmed that L\&M was generally not positioned among full flavored brands. Compared to the "Fandom movements" for the before-and-after measurements of the control group, there was no significant shift in the position of L\&M 6 weeks after the advertising campaign began.
Perry, Izraeli, and Pery (1976) used SSA to track changes in Israelis' perceptions of Canada as a vacation spot before and affer the introduction of direct flights to Canada. In this study considerable change in perception was obvious.

The differences between the two studies are instructive. Five months elapsed between measurement occasions in the vacation study. Only 6 weelss elapsed between measurement occasions in the cigarette study. The increased time alone could produce perceptual changes. The first measurement occurred before the air route was established in the vacation study. Thus, the advertising program for vacationing by air to Canada was much more distinctive than the ads for a reblended cigarette. Only people who indicated that they either had traveled abroad during the last 2 years or had intended to do so in the subsequent 2 years were included in the Perry et al. (1976) study. This is a very specific and select audience. (Although only smokers were used in the Smith and Lusch, 1976, study, this was a much less exclusive group.) Finally, no control group was available in the Perry et al. (1976) study. Though the perceptual changes seem large and systematic, Perry et al, did not compare the changes to random movement. The Hanno and Jones (1973) jackknife technique could have been used to test changes against random movements.

In the second area, dealing with the compatability of brand images and slogans, Green and McMennamin (1973) briefly described three studies in which MDS addressed such advertising problems. The first case dealt with the evaluation of 15 potential new slogans for a soft drink. MDS showed that 11 of the slogans "were perceived as more closely associated with the images of one or more competitive brands than the firm's own brand' ( $p$. 502). In the second case a cereal marketer found that an advertising campaign emphasizing the good taste and high nutritional value succeded in positioning their cereal closer to the "good tasting" cereals than any of the other high nutrition cereals. In the third case, five potential advertising copy ideas for an over-the-counter drug were evaluated in an MDS study of physicians, since physicians" recommendations were the source of the early pur- 
chases of the drug. The firm's favorite appeal was perceived by the physicians as being more relevant to the leading (competitor's) product. The most popular appeal was thought, before the study, to be too "soft sell." Green and McMennamin (1973) proceeded by providing a detailed illustration of how market position analysis could help develop an advertising strategy for fabric softeners. As indicated earlier, this approach could be useful in problems related to branding.

Finally, one of the most fascinating uses of MDS in marketing was Clarke's (1978) merging of MDS and econometric analysis to expand the scope of competitive advertising models. He conjectured:

... it would seem that the advertising of two brands which are considered close substitutes for each other should affect each other's sales more than would the advertising of the third brand which is not viewed by consumers as a near substitute. (p. 1,687)

He described a situation in which Products $A$ and $\mathbb{B}$ are close together in a product space and Product $C$ is relatively far away. A differential cross-elasticity (i.e., the advertising expenditures of Product $\mathbb{B}$ should have a different impact on sales for Product $A$ than the advertising expenditures of Product C would have on Product $A$ ) would be expected. For the case in which an ideal point has been imbedded in the product space, relative distance to the ideal point replaced interproduct distances in Clarke's (1978) analysis. He developed an advertising modification function involving expenditures and either interproduct distance or distance to the ideal point. This is a ratio scale analysis but does nof encounter Hauser and Simmie's (1981) problem with arbitrary origins, since Clarke (1978) used ratio distances within the configuration, not scale values for products on the axes. Clarke derived self-elasticities and cross-elasticities for advertising expenditures which do account for perceptual positioning. He also derived an expression for optimal advertising expenditures. His theoretical developments overshadowed his empirical demonstration. The illustration dealt with 9 anonymous brands in a 100 brand market. Similarities were collected from students some 10 years after the last data in the econometric stream were gathered. Such an illustration showed only that the estimates could be produced. There is almost no substantive explanation for the fact that particular brands enjoyed differentially effective advertising.

\section{Facế Finding and Analysis}

Marketing researchers have made many methodological contributions to MDS research. This section reports contributions to understanding response rate, time, and accuracy; validity, reliability, and stability; and robustness of data collection procedures as well as robustness of the scaling algorithms.

\section{Data Collection-Response Rate, Time, and Aceireacy}

Neidell's (1972) comparison of data collected by triadic combinations, rotating anchors (i.e., the conditional rank order task), and semantic differential scales was in much the same style as earlier research on unidimensional methods (cf. Greenberg \& Collins, 1966; Kassarjian \& Nakanishi, 1967; van de Sandt, 1970). Neidell (1972) found rotating anchor points were comparable to semantic differential ratings in terms of quality and quantity of responses in mail surveys. Both methods were better than triadic combinations of these criteria.

Henry and Stumpf (1975) and McIntyre and Ryans (1977) added consideration of time and accuracy to their analysis of different data collection techniques for MDS. Henry and Stumpf (1975) varied set size and studied rank ordering, triadic comparison, and anchor point rankings. All were compared in terms of time, and the last two were compared for accuracy in terms of the number of intransitivities. There was no significant difference in accuracy, but the time analysis ranked anchor point methods as fastest, followed by rank ordering and triadic comparisons. MicIntyre and Ryans (1977) compared graded paired comparisons to the conditional rank order task used by Henry and Stumpf (1975). Graded paired comparisons turned out to be faster, without significant loss of accuracy. Graded 
paired comparisons were perceived by respondents to be a less boring and a less difficult task.

\section{DAfa Callection- Validind

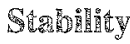

Summers and MacKay (1976) found only a modest correlation of judgments (rank order similarities) over a 1 -month period, only modest congruence in the individual perceptual spaces over this time period, and only modest ability of individuals to select a mapping of their own judgments from an aggregate map. Narayana (1976), on the other hand, found no significant difference in soft drink perceptions over 10 weeks. The major difference between these two studies indicates that if it is desirable to emphasize stability, single analysis should be done (e.g., INDSCAL) over occasions, as did Narayana, and changes should be looked for in weights. If it is desirable to emphasize instability, raw judgment vectors should be correlated, as did Summers and MacKay, or individual level perception spaces should be matched.

Moinpour, McCullough, and MacLachlan (1976) showed that if there can be control for structural shifts in frames of reference, INDSCAL analysis of shifts in salience over time can be an effective, conservative method for tracing the impact of persuasive communications. Day, Deutscher, and Ryans (1976) added level of aggregation to their study of reliability. 侕igh reliability with relatively poor fits indicated substantial heterogeneity among respondents. Their coefficient of reliability compared the rank order correlation of the original rankings and the later rankings with the rank order correlation of the first ranking and the repeated judgments, assuming their worst possible values. Deutscher (1982) has reviewed these reliability studies in more detail.

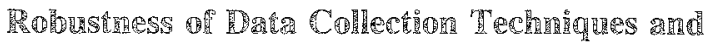

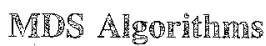

Greer and Rao (1971a) studied the ability of individual differences models to recover synthetic configurations. The letter " $R$ " was represented as 15 points in a two-dimensional space. Fifteen sub- jects were simulated by differentially shrinking or stretching the configuration. Into each configuration eight "property vectors" were imbeddled at random angles from the origin, and the eight reflections of those vectors were also imbedded. The "rating" of each point on each vector became one of the 16 elements in each individual's profile. Excellent recovery of the interpoint distances between pairs of profiles could be obtained from the ratings using multiple discriminant analysis, factor analysis of scalar products, INDSCAL analysis, TORSCA on the average distances, and M-D-SCAL IV using the individual differences, nonmetric option. For comparison, the ratings were downgraded to zeros and ones, with mean or higher ratings receiving the one. This was to simulate the effect of Steffire's (cf. Brown et al., 1968) data collection procedures. For the zero-one data interpoint distance, correlations between final and original configurations ranged from about. 76 to about -.02 , with factor analysis of scallar products and M-D-SCAL IV showing the worst recovery.

Green (1975b) summarized earlier simulation results on the recovery of structure in structureless data and reported that the simple integer-rank transformations of dissimilarities prior to nonmetric MDS was effective in minimizing the impact of strange transformations of distances. Regarding metric MDS he found that selection of the appropriate additive constant did have a pronounced impact on the recovery of structure. Rao and Katz (1971) simulated large data sets collected by seven different procedures. Although no meihod recovered siructure perfectly, the pick-k-and-order methods produced better recoveries than the subjective grouping methods (e.g., sort into $k$ groups). Individual differences models produced poorer recoveries than the group scaling methods, and nonmetric group methods performed better than metric group methods.

Whipple (1976) compared data collection methods and nonmetric MDS algorithms. Four preference rankings and one triadic preference ranking, bipolar ratings, attribute-cued rankings (e.g., the objects are ranked on the attribute of product safety), rotating anchor point rankings, and triadic proximity comparisons among seven children's toys

Downloaded from the Digital Conservancy at the University of Minnesota, http://purl.umn.edu/93227. May be reproduced with no cost by students and faculty for academic use. Non-academic reproduction requires payment of royalties through the Copyright Clearance Center, http://www.copyright.com/ 
formed mine data sets, which were scaled using five nonmetric MDS routines, i.e., elastic MDS (EMD; McGee, 1966), M-D-SCAL 5, TORSCA, SSA-I, and KYYST. Young and Appelbaum (1968) showed all these routines to be minimized by the same set of scale values even though the objective functions varied for some. A KYST analysis of the $21 \mathrm{in-}$ terpoint distances from each of the 45 solutions (i.e., 9 times 5) showed that there was no algorithmic difference, that all the preference ranking solutions clustered together, and that the bipolar ratings all clustered tightly, as did the atributecued rankings and the direct judged proximities.

Green and Maheshwari (1970) simulated conditional rank order data from an underlying configuration and varied the method of analysis (TORSCA versus direct unfolding using M-D-SCAL IV), the extent of ties in the data, and the level of noise. A three-way ANOVA on Fisher's 2 from the recovery correlations showed significant interactions between level of ties and level of error; significant interaction between method of analysis and level of error, and significant main effects for analyses, level of ties, and level of error. Jain and Pinson (1976) used MANOVA to investigate the effects of order of presentation, attentional instructions, and degree of commitment. In judging eight U.S. cities, no significant differences were found.

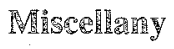

Day and Heeler (1971) compared principal components analysis, hierarchical clustering, and nonmerric MDS as a basis for clustering. The clusters were to be used as a matching device for in-store experiments (cf. Green, Frank, \& Robinson, 1967a). Principal components was chosen over nonmetric MDS "because it was more economical and did not appear to distort the data excessively" (p. 346). Hauser and Koppelman (1979) favored factor analysis over discriminant analysis and over similarity scaling for producing perceptual maps. They used predictive validity, interpretability, and ease of use as their criteria. Although some part of their conclusion seems application specific (i.e., modeling shopping center images), the controversy regarding the best method for perceptual mapping continues.
Worthy of mention is the early exchange of articles and letters to the editor on distance measures in cluster analysis (Morrison, 1967; Shuchman, 1967) and nonmetric MDS (Green, Frank, \& Robinson, 1967b; Green \& Rao, 1969). In response 10 the very high expectations set by these early discussions of MDS, Green, Frank and Robinson (1967b) ended by noting, "we tried to build a dog house. Already you want to throw a convention in it!!" (p. 841).

\section{Tew Prodict Rodels}

Understanding of the use of MDS in comprehensive new-product models is aided by the delineation of stages given in Shocker and Srinivasan's (1979b) review of product concept generation and evaluation studies. They discussed five stages: (1) determination of the relevant product-markets, (2) identification of the determinant attributes, (3) creation of the perceptual product spaces, (4) modeling individual or segment decision making, and (5) evaluation of/search for new product concepts. Since the frrst four of these directly involve MDS, they will be discussed in tum.

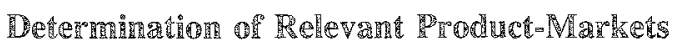

The determination of relevant product-markets is the stage of defining or articulating the market in which the new product must compete. Srinivasan and Shocker (1973) suggested use of Steffire's (cf. Brown et al., 1968) product by usage matrix, which could be multidinensionally scaled to articulate the market. A possibly useful analysis here would be Levine's (1979) analysis of "pick-any" data (cf. Holbrook, Moore, \& Winer 1982). Although the analysis was developed for preference data, its adaption to market definition seems promising. As indicated earlier, respondents would be asked to select all the products they would consider purchasing. Products would be positioned at the center of all the respondents who selected them. Products close together would tend to be those that were the most intersubstitutable.

Srinivasan and Shocker (1973) suggested nonmetric MDS of similarities for market determina- 
tion. Many illustrations of this type of application have been reviewed earlier, but several methodological problems remain. To allow consumers to generate the market definition should incline researchers to specify an overly large list of potential competitors. At this early stage of development, the focus should be broad. Paired comparisons, conditional rankings, ratings, or other standard data collection techniques would take a great deal of time with long product lists and would lead to a great deal of missing data or ratings of unfamiliar products. The pick-any format of Levine's procedure resolves some of these problems and merits more study.

\section{Identirication of the Determinant Atroibutes}

Determinant attributes are traditionally defined as those attributes that distinguish the product alrematives and are probably determinants of brand choice. One should be cautious in emphasizing the need for determinant attributes to distinguish among existing alternatives. If an important attribute does not distinguish among existing alternatives, new alternatives might be positioned so as to be distinct along that attribute.

MDS has obvious uses here. Along with other techniques, MDS was fused for this purpose by Lehmann (1971b), Wind (1973, 1977), Srinivasan and Shocker (1973), Urban (1975), and Hauser and Urban (1977). The advantage of MDS in this context is that it allows the researcher to discover the relevant attributes. The similarities question is probably the most neutral question in the social sciences. It allows the respondent to bring a personal frame of reference to the judgment task, rather than having one imposed by a prescribed list of attributes on which the product alternatives are rated. With this neutrality comes the potential problems of interpretability, the possibility that the results will be a mixture of class and quantitative variation, rather than a strict dimensional representation, and the possibility that dimensions relevant for similarities judgments are not relevant for choice.

The solution of these problems does not come from accepting only a few dimensions in an MDS space. The emphasis of marketing researchers on low dimensional MDS representations could mean that only the obvious will be discovered. It would be wise to remember the words of Heracleitus of Ephesus, "If you do not expect it, you will not find out the unexpected, as it is hard to be sought out and difficult."

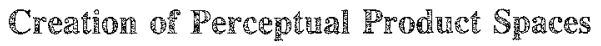

The creation of perceptual product spaces cam be achieved by factor analysis, discriminant analysis, direct measurement of "determinant attributes," or MDS. Wind (1973, 1977), Hustad, Mayer, and Whipple (1975), Urban (1975), and Hauser and Urban (1977) used MDS. A11 except Urban assumed that different market segments have common percepual frames of reference. Urban considered clustering individuals on their INDSCAL weights, clustering factor scores, or determining clusters by obverse factor analysis or by the Tucker and Messick (1963) model. Shocker and Srinivasan (1979b) considered a common framework obligatory: "this is because evaluation and/or search for desirable new concepts requires that it be feasible to evaluate a large number of candidates efficiently. ... Such tasks are difficult, and would be virtually impossible were it necessary to coordinate multiple customer spaces with a single manufacturer's space" (p. 167).

The emphasis on low dimensionality and the rotational determinancy of techniques such as INDSCAL may not be the allies of the marketing researcher in the creation of perceptual product spaces. What would be beneficial is a representation of individual differences that had some perceptual dimensions common to all and some dimensions that, although relevant to some subsets of individuals, were not relevant to others. Such a representation could create distinct, perceptually homogeneous segments but with a sense of which dimensions were shared over segments and which dimensions were not. Although it might be possible to achieve this representation with a high dimensional INDSCAL solution, it seems that something from the family of individual differences models for MDS (Tucker, 1972; Tucker \& Messick, 1963) would be more suited for the task. Evaluation of new 
concepts in this overall higher dimensional representation might present some problems, but there is no reason to expect them to be insurmountable.

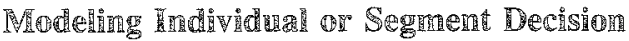

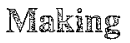

Srinivasan and Shocker (1973) imbedded ideal points into the product space with their LINMAP procedure. They modeled the probabilities of all choices as a decreasing function of distance from the ideal point and modeled first choice as the producs nearest the ideal point. Hustad et al. (1975) mapped preferences using PREFMAP but did not model choice (cf. Pessemier, 1975; Pessemier \& Root, 1973). Pessemier (1975) mapped his dollar merric preferences into the product space with PRERMAP and implicitly used a Luce (1959) model to represent choice (cf. Pessemier, 1975; Pessemier \& Root, 1973). Wind $(1973,1977)$ imbedded ideal points with PREFMAP and indicated that probability of purchase was a decreasing function of distance from the ideal point. Urban (1975) also used PREFMAP or LINMAP as a basis for predicting long-run market share. Hauser and Urban (1977) used the same preference mapping but used the multinomial logit model to forecast market share, as did Hauser and Koppelman (1979) and Hauser and Simmie (1981).

The linkages from perceptions of preferences to choice probabilities or market shares are important for marketing research. Forecasts of market-level activity (e.g., market share) are best done by procedures that integrate consumer-level measurements (e.g., MDS results) with market-level measurements (e.g., price, promotional expenditures, availability). This would seem to make the multinomial logit model a robust choice, since information from numerous sources could be combined with MDS results into market forecasts. A very large stumbling block, however, is the independence from irrelevant alternatives (IA) assumptions that goes along with traditional applications of the multinomial logit model. Particularly in a new product context, it seems more reasonable to model explicitly the effects of changes in the composition of choice sets than to assume, in essence, that there are no effects.

Batsell (1980, 1981) has been working on an MDS approach to the IIA problem. As did Clarke (1978) in his work on differential advertising crosselasticities, Batsell $(1980,1981)$ has used interbrand distances as a measure of substitutability which combines with a measure of utility to predict choice probabilities. Currim (1982) described his own and other recent attacks on the problem of the IIA assumption. Cooper and Nakanishi (1983) have shown how simply standardizing variables in each choice situation overcomes the $\mathbb{I} \mathrm{A}$ assumption in logit models or multiplicative competitive interaction (MCI) nodels.

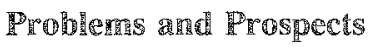

MDS does not answer all the questions which a marketing researcher can pose. Within a less than comprehensive mandate, there seem to be three discernible directions for MDS in marketing research.

The first is toward a finer grained inspection of individual and group perceptions. One of the lingering problems in this direction concerns data omitted through prudence rather than through caprice. If individuals are not familiar enough with some collection of choice alternatives to make judgments about them, it is prudent not to force these judgments. Levine's (1979; cf. Holbrook, Moore, \& Winer, 1982) "pick any" MDS model deals well with this issue within its scope of applicability. How relevant set membership is modeled, however, and its impact on spatial representations, requires more general attention. Though Hauser and Koppelman (1979 have cast this as a special problem for MDS, it is no less a problem for factor analysis or discriminant analysis. This is part of a larger problem concerning the representation of individual differences. As marketing researchers move tow ard basing perceptual spaces on very large samples of consumers, a more richly articulated representation of individual or segment differences will be useful. This will be true for fundamentally symmetric MDS problems as well as fundamentally asymmetric MDS problems. 
The second direction deals with merging MDS with other consumer-based measurements (e.g., normative beliefs), then, in tum, merging consumer-level measurements with market-level measurements. Although the former data base is primarily cross-sectional (e.g., over individuals or segments), the latter is primarily a longitudinal data base. Some of the potential of this merger is communicated by Clarke's (1978) work. In addition to promotions expenditures, there are other marketlevel influences (e.g., price and distribution). A longindinal analysis of market-level variables might be done to estimate parameters in an MCI model or in a multinominal logit model. These parameters might then be used in a cross-sectional analysis in which parameters for the consumer-level variables are estimated. With market-level choice as the crirerion, and the reality of scamner data as a purchaseby-purchase account of market activity, there is much to be explained.

The third direction deals with the representation of change on a broader scale than the introduction of a new product into an existing market. The current new-product models and methods might not have allowed marketing researchers to forecast the video game and home computer revolution. For products that essentially create new markets there needs to be study of the structure and intersubstitutability of product classes or, as in Ritchie (1974), of the relations among alternative uses of leisure time.

In his 1975 review of MDS in marketing, Green (1975a) wondered whether or not MDS had fulfilled its early promise. With 8 more years of experience, it seems that it has. The new generation of sextbooks on MDS (Coxon, 1982; Davison, 1983; Schiffman, Reynolds, \& Young, 1981) promise to prepare the next generation of MDS researchers even better than the pioneers. As long as MDS is not expected to solve all the complex problems of the field, it should continue to be a powerful and useful methodology in the arsenal of marketing researchers.

\section{Reererences}

Albers, S., \& Brockhoff, B. A procedure for new prod- uct positioning in an attribute space. European Journal of Operational Research, 1977, 1, 230-238.

Arabie, P., Carroll, J. D., DeSarbo, W., \& Wind, J. Overlapping clustering: A new method for product positioning. Journal of Marketing Research, 1981, $23,310-317$.

Bateson, J., \& Greyser, S. The effectiveness of the knowledge generation and diffusion process in marketing-Some considerations and empirical findings (Paper No. 82/4). London: The London Business School, July 1982.

Batsell, R. R. A market share model which simultaneously captures the effects of utility and substitutability (Working Paper 80-007). Philadelphia: University of Pennsylvania, The Wharton School, 1980.

Batsell, R. R. A multiattribute extension of the Luce model which simultaneously scales utility and substitutability. In J. Huber (Ed.), The effects of item similarity on choice probability: A collection of working papers from a conference at Quail Roost. Durham, NC: Duke University, 1981.

Bechtel, G. G. Multidimensional preference scaling. The Hague: Mouton, 1976.

Bechtel, G. G. Metric information for group representations. In 1. Borg (Ed.), Multidimensional data representations: When and why. Am Arbor MH: Mathesis Press, 1981 .

Bechtel, G. G., \& O'Connor, P. J. Testing micropreference structures. Journal of Marketing Research, $1979,16,247-257$.

Best, R. J. The predictive aspects of a joint-space theory of stochastic choice. Journal of Marketing Research, $1976,13,198-204$.

Borden, H. The concept of the marketing mix. Journal of Advertising Research, 1964, 4, 2-7.

Brown, M. P., Cardozo, R. N., Cunningham, S. M., Salmon, W. J., \& Sultan, R. G. P. Maxwell House division. In Problems in marketing. New York: McGraw-Hill, 1968.

Carroll, J. D., \& Chang, J. J. Analysis of individual differences in multidimensional scaling via an $N$-way generalization of "Eckart-Young" decomposition. Psychometrika, 1970, 35, 283-320.

Carroll, J. D. Individual differences and multidimensional scaling. In A. K. Romney, R. N. Shepard, \& S. B. Nerlove (Eds.), Multidimensional scaling; Theory and applications in the behavioral sciences (Vol. 2). Applications. New York: Seminar Press, 1972.

Carrol1, I. D., \& Chang, J. J. Relating preference data to multidimensional scaling via a generalization of Coombs' unfolding model. Paper presented at the annual meeting of the Psychometric Society, Madison WI, April 1967.

Clarke, D. G. Strategic advertising planning: Merging multidimensional scaling and econometric analysis. Management Science, 1978, 24, 1687-1699. 
Cooper, L. G. A new solution to the additive constant problem in metric multidimensional scaling. Psychometrika, 1972, 37, 311-322.

Cooper, L. G. A multivariate investigation of preferences. Multivariate Behavioral Research, 1973, 8, $253-272$.

Cooper, L. G., \& Nakanishi, M. Standardizing variables in multiplicative choice models. Journal of Consumer Research, 1983, 10, 96-108.

Coxon, A. P. M. The user's guide to multidimensional scaling. Exeter: Heineman, 1982.

Currim, I. Predictive testing of consumer choice models. Journal of Marketing Research, 1982, 19, 208-222.

Davison, M. L. Multidimensional scaling. New York: Wiley-Interscience, 1983.

Day, G. Evaluating models of attitude structure. Journal of Marketing Research, 1972, 9, 279-286.

Day, G. S., Deutscher, T., \& Ryans, A. B. Data quality, level of aggregation, and nonmetric multidimensional scaling solutions. Journal of Marketing Research, 1976, $13,92-97$.

Day, G. S., \& Heeler, R. M. Using cluster analysis to improve marketing experiments. Journal of Marketing Research, 1971, 8, 340-347.

Deutscher, $T$. Issues in data collection and reliability in marketing multidimensional scaling studies-Implication for large stimulus sets. In $\mathbb{R}$. G. Golledge \& J. N. Rayner (Eds.), Proximity and preference: Problems in the multidimensional analysis of large data sets. Minneapolis: University of Minnesota Press, 1982.

Doyle, P., \& McGee, J. Perceptions of and preferences for alternative convenience foods. Joumal of the Marketing Research Society, 1973, 15, 24-34.

Drasgow, F., \& Jones, $\mathbb{E}$. Multidimensional scaling of derived dissimilarities. Multivariate Behavioral Research, 1979, 14, 227-244.

Frank, R. E., \& Green, P. E. Numerical taxonomy in marketing analysis: A review article. Journal of Marketing Research, 1968, 5, 83-93.

Fry, J. N., \& Claxton, J. D. Semantic differential and nonmetric multidimensional scaling descriptions of brand images. Journal of Marketing Research, 1971 , $8,238-240$.

Green, P. E. Measurement and data analysis. Journal of Marketing, 1970, 34, 15-17.

Green, P. E., A multidimensional model of productfeatures association. Journal of Business Research, $1974,2,107-118$.

Green, P.E., On the robustness of multidimensional scaling techniques. Journal of Marketing Research, $1975,12,73-81$. (a)

Green, P. E. Marketing application of MDS: Assessment and outlook. Journal of Marketing, 1975, 39, 24-31. (b)

Green, P. E., \& Carmone, F. J. The performance struc- ture of the computer market: A multivariate approach. The Economic and Business Bulletin, 1968, 21, 111 .

Green, P. E., \& Carmone, F. $\mathbb{~}$. Multidimensional scaling: An introduction and comparison of nonmetric unfolding techniques. Journal of Marketing Research, $1969,6,330-341$.

Green, P. E., \& Carmone, F. J. Multidimensional scaling and related techniques in marketing analysis. Boston: Allyn \& Bacon, 1970.

Green, P. E., \& Camone, F. J. The effect of task on intra-individual differences in similarities judgments. Multivariate Behavioral Research, 1971, 6, 433-450.

Green, P. E., \& Carmone, F. J. Marketing research applications of nommetric multidimensional scaling methods. In A. K. Romney, R. N. Shepard, \& S. B. Nerlove (Eds.), Multidimensional scaling: Theory and applications in the behavioral sciences (Vol. 2). Applications. New York: Seminar Press, 1972.

Green, P. E., Carmone, F. J., \& Fox, L. B. Television program similarities: An application of subjective clustering. Journal of the Market Research Society, $1969,11,70-90$.

Green, P. E., Carmone, F. J., \& Robinson, P. J. Nonmetric scaling methods: An exposition and overview. Wharton Quarterly, 1968, 27-40.

Green, P. E., \& Devita, M. T. An interaction model of consumer utility. Journal of Consumer Research, 1975 , $2,146-153$.

Green, P.E., Frank, R. E., \& Robinson, P. J. Cluster analysis in test market selection. Management Science, Series B, 1967, 13, B387-B400. (a)

Green, P.E., Frank, R. E., \& Robinson, P. I. Letter to the editor. Management Science, Series B, 1967 , 13, B840-B841. (b)

Green, P. E., \& Greenberg, M. G. Ordinal methods in multidimensional scaling and data analysis. In R. Ferber (Ed.), Handbook of marketing research. New York: McGraw-Hill, 1974.

Green, P.E., \& Maheshwari, A. Common stock perception and preference: An application of multidimensional scaling. Journal of Business, 1969,42 , 439-457.

Green, P. E., \& Maheshwari, A. A note on the multidimensional scaling of conditional proximity data. Journal of Marketing Research, 1970, 7, 106-110.

Green, P. E., Maheshwari, A., \& Rao, V. R. Selfconcept and brand preference: An empirical application of multidimensional scaling. Journal of the Marketing Research Society, 1969, 11, 343-360. (a)

Green, P. E., Maheshwari, A., \& Rao, V. R. Dimensional interpretation and configuration invariance in multidimensional scaling: An empirical study. Multivariate Behavioral Research, 1969, 4, 159-180. (b)

Green, P. E., \& McMennamin, J. L. Market position analysis. In S. H. Britt (Ed.), The Dartnell marketing 
managers handbook. Chicago: The Dartnell Corporation, 1973.

Green, P. E., \& Rao, V. R. A note on proximity measures and cluster analysis. Journal of Marketing Research, $1969,6,359-364$.

Green, P. E., \& Rao, V. R. Multidimensional scaling and individual differences. Journal of Marketing Research, 1971, 8, 71-77. (a)

Green, P. E., \& Rao, V. R. Conjoint measurement for quantifying judgmental data. Joumal of Marketing Research, 1971, 8, 335-363. (b)

Green, P. E., \& Rao, V. R. Configuration synthesis in multidimensional scaling. Journal of Marketing Research, 1972, 9, 65-68. (a)

Green, P. E., \& Rao, V. R. Applied multidimensional scaling: A comparison of approaches and algorithms. New York: Holt, Rinehart, \& Winston, 1972. (b)

Green, P. E., \& Wind, Y. Multiatribute decisions in marketing: A measurement approach. Hinsdale $\mathbb{I L}$ : The Dryden Press, 1973.

Green, P. E., Wind, Y., \& Claycamp, H. J. Brand features congruence mapping. Journal of Marketing Research, 1975, 12, 306-313.

Green, P. E., Wind. Y., \& Jain, A. K. A note on measurement of a social-psychological belief system. Jownal of Marketing Research, 1972, 9, 204-208.

Green, P. E., Wind, Y., \& Jain, A. K. Analyzing freeresponse data in marketing research. Joumal of $\mathrm{Mar}$ keting Research, 1973, 10, 45-52.

Greenberg, A., \& Collins, S. Paired comparison taste tests: Some food for thought. Journal of Marketing Research, 1966, 3, 76-80.

Greenberg, M. G., \& Green, P. E. Multidimensional scaling. In $\mathbb{R}$. Ferber (Ed.) Handbook of marketing research. New York: McGraw-Hill, 1974.

Guttman, L. A general nonmetric technique for finding the smallest coordinate space for a configuration of points. Psychometrika, 1968, 33, 469-504.

Hanno, M. S., \& Jones, L. E. Effects of a change in reference person on the multidimensional structure and evaluations of trait adjectives. Joumal of Personality and Social Psychology, 1973, 28, 368-375.

Harshman, R. H., Green, P. E., Wind, Y., \& Lundy, M. E. A model for the analysis of asymmetric data in marketing. Marketing Science, 1982, 1, 205-242.

Hauser, J. R., \& Koppelman, F. S. Alternative perceptual mapping techniques: Relative accuracy and usefulness. Journal of Marketing Research, 1979, 16, 495-506.

Hauser, I. R., \& Simmie, P. Profit maximizing perceptual positions: An integrated theory for the selection of product features and price. Management Science, $1981,27,33-56$

Hauser, J. R., \& Urban, G. L. A normative methodology for modeling consumer response to innovation. Operations Research, 1977, 25, 579-619.
Henry, W. A., \& Stumpf, R. F. Time and accuracy measures for alternative mulidimensional scaling data collection methods. Journal of Marketing Research, $1975,12,165-170$.

Holbrook, M. B., Moore, W. L., \& Winer, R. S. Constructing joint spaces from pick-any data: $A$ new too for consumer analysis. Journal of Consumer Research, 1982, 9, 99-105.

Holbrook, M. B., \& Williams, R. S. A test of the correspondence between perceptual spaces based on pairwise similarity judgments collected with and without the inclusion of explicit ideal objects. Joumal of Applied Psychology, 1978, 63, 373-376.

Hopkins, D. S. P., Larreche, J.-C., \& Massy, W. F. Constrained optimization of a university administrator's preference function. Management Science, 1977 , $24,365-377$.

Howard, N., \& Harris, B. A hierarchical grouping routine, IBM $360 / 65$ FORTRAN program. Philadelphia PA: University of Pennsylvania Computer Center, 1966.

Huber, J. Predicting preferences on experimental bundles of atrributes: A comparison of models. Joumal of Marketing Research, 1975, 12, 290-297.

Hustad, T. P., Mayer, C. S., \& Whipple, T.W. Consideration of context differences in product evaluation and market segmentation. Journal of the Academy of Marketing Science, 1975, 3, 34-47.

Jain, A. K., \& Pinson, C. The effect of order of presentation of similarity judgments on multidimensional scaling results: An empirical examination. Journal of Marketing Research, 1976, 13, 435-439.

Johnson, R. M. Market segmentation: A strategic management tool. Journal of Marketing Research, 1971 , $8,13-18$.

Johnson, S. C. Hicrarchical clustering schemes. PSychometrika, 1967, 32, 241-254.

Kassarjian, H. H., \& Nakanishi, M. A study of selected opinion measurement techniques. Journal of Marketing Research, 1967, 4, 148-153.

Kinnear, T. C., \& Taylor, J. R. The effect of ecological concern on brand perceptions. Journal of Marketing Research, 1973, 10, 191-197.

Klahr, D. Decision making in a complex environment: The use of similarity judgments to predict preferences. Management Science, 1969, 15, 595-618.

Klahr, D. A study of consumer's cognitive structure of cigarette brands. Journal of Business, $1970,43,190-$ 204.

Krampf, R. F., \& Williams, J. D. Multidimensional scaling as a research tool: An explanation and application. Journal of Business Research, 1974, 2, 157175.

Kruskal, J. B. Multidimensional scaling by optimizing goodness of fit to a nonmetric hypothesis. Psychometrika, 1964, 29, 1-27. (a)

Kruskal, J. B. Nonmetric multidimensional scaling: A 
numerical method. Psychometrika, 1964, 29, 115128. (b)

Kruskal, J. B. How to use M-D-SCAL. A program for multidimensional scaling and multidimensional unfolding (Version 4 and $4 M$ of M-D-SCAL, all in FORTRAN IV). Murray Hill NJ: Bell Telephone Laboratories, 1968. (mimeograph)

Lancaster, $\mathbb{K}$. A new approach to consumer theory. Journal of Political Economy, 1966, 74, 132-157. (a)

Lancaster, $\mathbb{K}$. Change and innovation in the technology of consumption. American Economic Review, 1966, $56,14-23$. (b)

Lancaster, L. Consumer demand: A new approach. New York: Columbia University Press, 1971.

Lehmann, D. R. Television show preference: Application of a choice model. Journal of Marketing Research, 1971, 8, 47-55.

Lehmann, D. R. Evaluating market strategy in a multiple brand market. Joumnal of Business Administration, 1971 , 3, 15-26. (b)

Lehmann, D. R. Judged similarity and brand-switching data as similarity measures. Joumal of Marketing Research, 1972, 9, 331-334.

Lehmam, D. R. Some alternatives to linear factor analysis for variable grouping applied to buyer behavior variables. Journal of Marketing Research, 1974, 11, 206-213.

Levine, I. H. Joint-space analysis of "pick-any" data: Analysis of choices from an unconstrained set of alternatives. Psychometrika, 1979, 44, 85-92.

Luce, R. D. Individual choice behavior. New York: Willey, 1959.

Mackay, D. B., \& Olshavsky, R. W. Cognitive maps of retail locations: An investigation of some basic issues. Joumal of Consumer Re search, 1975, 2, 197 205.

Mauser, G. A. Positioning political candidates-An application of concept evaluation techniques. Journal of the Marketing Research Society, 1980, 22, 181-191.

McGee, $V$. The multidimensional analysis of "elastic" distance. The British Journal of Mathematical and Statistical Psychology, 1966, 19, 181-196.

Mclntyre, S. H., \& Ryans, A. B. Time and accuracy measures for alternative multidimensional scaling data collection methods: Some additional results. Journal of Marketing Research, 1977, 16, 607-610.

Moinpour, R. J., McCullough, $\mathbb{I}$. M., \& MacLachlan, D. L. Time changes in perception: A longitudinal application of multidimensional scaling. Joumal of Marketing Research, 1976, 13, 245-253.

Moore, W. L. Predictive power of joint space models constructed with composition techniques. Journal of Business Research, 1982, 10, 217-236.

Moore, W. L., \& Holbrook, M. B. On the predictive validity of joint-space models in consumer evaluations of new concepts. Journal of Consumer Research, 1982 , $9,206-210$.

Moore, W. L., Pessemier, E. A., \& Little, T.E. Predicting brand purchase behavior: Marketing application of the Schönemann and Wang unfolding model. Journal of Marketing Research, 1979, 16, 203-210.

Morgan, N., \& Purnell, J. Isolating openings for new products in a multi-dimensional space. Journal of the Marketing Research Society, 1969, 11, 245-266.

Morrison, D. G. Measurement problems in cluster analysis. Management Science, Series B, 1967, 13, B775B780.

Narayana, C. L., The stability of perceptions. Journal of Advertising Research, 1976, 16, 45-49.

Neidell, L. A. The use of nonmetric multidimensional scaling in marketing analysis. Journal of Marketing, $1969,33,37-43$.

Neidell, $\mathbb{L}$. A. Procedure for obraining similarities data. Journal of Marketing Research, 1972, 9, 335-337.

Olshavsky, R. W., Mackay, D. B., \& Sentell, G. Perceptual maps of supermarket locations. Journal of $A p$ plied Psychology, 1975, 60, 80-86.

Pekelman, D., \& Sen, S. K. Mathematical programming models for the determination of attribute weights. Management Science, 1974, 20, 1217-1229.

Percy, L. H. Multidimensional unfolding of profile data: A discussion and illustration with attention to badnessof-fit. Journal of Marketing Research, 1975, 12, 9399.

Perreault, W. D., Jr., \& Young, F. W. Alternating least squares optimal scaling: Analysis of nonmerric data in marketing research. Journal of Marketing Research, $1980,17,1-13$.

Perry, M. Izraeli, D., \& Perry, A. Image change as a result of advertising. Journal of Advertising Research, $1976,16,45-50$.

Pessemier, E. A. Market structure analysis of new product and market opportunities. Journal of Contemporary Rusiness, 1975, 4, 35-67.

Pessemier, E. A., Burger, P., Teach, R., \& Tigert. D. Using laboratory brand preference scale to predict consumer brand purchases. Management Science, Series $B, 1971,17, \mathrm{~B} 371-\mathrm{B} 385$.

Pessemier, E. A. \& Root, H. P. The dimensions of new product planning. Journal of Marketing, 1973, 37, $10-18$.

Rao, V. R. Changes in explicit information and brand perceptions. Joumal of Marketing Research, 1972, 9, $209-213$.

$\mathbb{R}$ ao, V.R., \& $\mathbb{K a t z}, \mathbb{R}$. Altemative multidimensional scaling methods for large stimulus sets. Joumal of Marketing Research, 1971, 8, 488-494.

Richie, J.R. B. An exploratory analysis of the mature and extent of individual differences in perception. Journal of Marketing Research, 1974, 11, 41-49. 
Roberts, M. L. \& Taylor, I. R. Analyzing proximity judgments in an experimental design. Joumal of Marketing Research, 1975, 12, 68-72.

Ross, J., \& Cliff, N. A generalization of the interpoint distance models. Psychometrika, 1964, 29, 167-176.

Ryans, A. B. Estimating consumer preferences for a new durable brand in an established product class. Journal of Marketing Research, 1974, 11, 434-443.

Schiffman, S. S., Reynolds, M. L., \& Young, F. W. Introduction of multidimensional scaling: Theory, methods, and applications. New York: Academic Press, 1981.

Schönemann, P., \& Wang, M. M. An individual differences model for the multidimensional analysis of preference data. Psychometrika, 1972, 37, 275-309.

Shepard, R. N., \& Carroll, J. D. Parametric representation of nonlinear data structures. In P. R. Krishnaiah (Ed.), International symposium on multivariate analysis, Dayton OH, 1965. New York: Academic Press, 1966.

Shocker, A. D., \& Srinivasan, V. A consumer-based methodology for the identification of new product ideas. Management Science, 1979, 20, 921-937. (a)

Shocker, A. D., \& Srinivasan, V. Multiatribute approaches for product concept evaluation and generation: A critical review: Joumal of Marketing Research, 1979, 16, 159-180. (b)

Shuchman, A. Letter to the editor. Management Science, Series B, 1967, 13, B688-B691.

Silk, A. J. Preference and perception measures in new product development: An exposition and review. In dustrial Management Review, 1969, 21-37.

Silk, A. J., \& Urban, G. L. Pre-test market evaluation of new packaged goods: A model and measurement methodology. Journal of Marketing Research, 1978, $15,171-191$.

Smith, R. E., \& Lusch, R. F. How advertising can position a brand. Joumal of Advertising Research, $1976,16,37-43$

Srinivasan, V., \& Shocker, A. D. Linear programming techniques for multidimensional analysis of preferences. Psychometrika, 1973, 38, 337-367.

Steffire, V. J. Market structure studies: New products for old markets and new markets (foreign) for old products. In F. Bass \& R. Frank (Eds.), Applications of the sciences in marketing. New York: John Wilcy \& Sons, 1968 .

Steffre, V. J. Some applications of multidimensional scaling to social science problems. In A. K. Romney, R. N. Shepard, \& S. B. Nerlove (Eds.), Multidimensional scaling: Theory and applications in the behavioral sciences (Vol. 2). Applications. New York: Seminar Press, 1972.

Summers, J. O., \& MacKay D. B. On the validity and reliability of direct similarity judgments. Joumal of Marketing Research, 1976, 13, 289-295.

Tucker, L. R. Factor analysis of double centered score matrices (ETS RM-56-3). Princeton NJ: Educational Testing Service, 1956.

Tucker, L. R. Comments on "Confounding of sources of variation in factor-analysis techniques." Psychological Bulletin, 1968, 70, 345-354.

Tucker, L. R. Relations between multidimensional scaling and three-mode factor analysis. Psychometrika, $1972,37,3-27$.

Tucker, L. R., \& Messick, S. An individual differences model for multidimensional scaling. Psychometrika, $1963,28,333-367$.

Turner, R. E. Market measures from salesmen: A multidimensional scaling approach. Journal of Marketing Research, 1971, 8, 165-172.

Urban, G. Perceptor: A model for product positioning. Management Science, 1975, 21, 858-871.

van de Sandt, $\mathbb{U}$. Incomplete paired comparisons using balanced lattice designs. Joumal of Marketing Research, 1970, 7, 246-248.

Whipple, T. W. Variation among multidimensionall scalling solutions: An examination of the effect of data collection differences. Journal of Marketing Re. search, 1976, 13, 98-103.

Wind, Y. A new procedure for concept evaluation. Jour. nal of Marketing, 1973, 37, 2-11.

Wind, Y. The perception of a firm's competitive position. In $\mathbb{F}$. M. Nicosia \& Y. Wind (Eds.), Behavioral models for market analysis: Foundations for marketing action. Hinsdale IL: The Dryden Press, 1977.

Wind, Y. Issues and advances in segmentation research. Joumal of Marketing Research, 1978, 15, 317-337.

Young, F. W., \& Appelbaum, M. I., Nonmetric multidimensional scaling: The relationship of several methods (Report No. 71). Chapel Hill NC: L. L. Thurstone Psychometric Laboratory, 1968

Young, $\mathbb{F}$. W. \& Torgerson, W. S. TORSCA IV program for Shepard-Kruskal multidimensional scaling analysis. Behavioral Science, 1967, 12, 498.

Young, S., Ott, L., \& Feigin, B. Some practical considerations in market segmentation. Journal of Marketing Research, 1978, 15, 405-412.

\section{Ackndwed}

I would like to acknowledge gratefully the suggestions of the special editors, Mark Davison and Lawrence Jones; the comments of Dominique Hanssens, Robert Meyer. and Allan Shocker; the help of Dan Jacobs in editing; and the special efforts of Jaime Tongue-Smith, Paricia McNally, and Lucy Gonzalez in manuscript preparation.

\section{Aduchor ${ }^{9}$ s Adtiless}

Send requests for reprints or further information to Lee G. Cooper, Graduate School of Management, University of Califomia, Los Angeles CA $90024, U . S . A$. 